\title{
PROBLEMA
}

Anuario de Filosofia

y Teoría del Derecho 1

\section{¿BAJO QUÉ CRITERIOS ES POSIBLE JUSTIFICAR QUE UNA LEY OTORGUE UN TRATO DESIGUAL EN EL EJERCICIO DE LOS DERECHOS FUNDAMENTALES?}

Carlos de la TORRE

Resumen:

De las muchas diferenciaciones que se presentan entre las personas de una sociedad, este artículo analiza una específica: cuando un trato desigual establecido por una ley constituye un trato discriminatorio. Se consideran los criterios que debe usar el juez para determinar si la distinción hecha por una norma - de los derechos y libertades fundamentales de las personas-descansa en una justificación racional y objetiva.

\begin{abstract}
:
Of several distinctions made between people in a society, this article addresses a specific question: when do we have a legal directive that is unfair and therefore discriminatory? The article puts forward a set of criteria that judges might use in order to determine if a distinction made by a legal directive has a rational and objective justification.
\end{abstract}


Sumario: I. Precisión de la problemática. II. Primera vía de solución. III. Segunda vía de solución. IV. Criterio material de valoración.

\section{PRECISIÓN DE LA PROBLEMÁticA}

El contenido esencial del derecho a no ser discriminado, es decir, la acción u omisión que el titular del derecho puede exigir jurídicamente de aquél en quien recae la obligación de no discriminar, consiste en el deber de no dar un trato desigual o establecer alguna distinción basada en algunas cualidades personales del sujeto activo que implique la restricción o vulneración de sus derechos fundamentales.

Esta definición, que de hecho ha sido adoptada por la gran mayoría de Constituciones democráticas y por los instrumentos internacionales de derechos humanos para sustanciar jurídicamente el principio de no discriminación, puede ser aplicada con toda facilidad a un conjunto amplio de distinciones que se han hecho a lo largo de la historia y que nos resultan indignantes y manifiestamente injustas, tales como restringir el derecho al voto exclusivamente a los varones blancos y propietarios, restringir las libertades públicas a las personas que no cumplen con ciertas características físicas, excluir de los puestos públicos a personas de religión distinta a la oficial o establecer ciertos puestos de trabajo como exclusivos para varones. Sin embargo, parece que no es posible aplicarla con tal facilidad a otro tipo de distinciones realizadas con base en ciertas características personales y que de igual manera afectan los derechos fundamentales de las personas. Algunos ejemplos pueden ser: el restringir el derecho al voto a mayores de 18 años, establecer un mínimo de años para poder contraer matrimonio, exigir que las condiciones de trabajo sean más benignas para una mujer embarazada o establecer una tasa impositiva mayor a una persona que tiene mayores ingresos que otra. De hecho, una labor fundamental que el derecho ha realizado a lo largo de la historia ha sido la de establecer un amplio conjunto de distinciones precisas en- 
tre supuestos de hecho diversos, así como un conjunto de distinciones en torno a las consecuencias jurídicas que deben aplicarse en situaciones análogas o similares. ${ }^{1}$

El caso es que resulta evidente que no toda distinción puede ser considerada una discriminación, incluso, aunque ésta haya sido hecha con base en las características o condiciones personales de una persona y se hayan limitado o restringido sus derechos fundamentales. Se requiere, además, que la distinción sea racionalmente injustificable o si se prefiere que se carezca de una razón suficiente para realizar dicha distinción. Ahora bien, esta respuesta no parece decirnos mucho. Por el contrario, el problema parece adquirir mayor profanidad al reconducirnos a la pregunta central que aquí trataré de abordar: ¿bajo qué criterios podemos considerar una distinción como racionalmente injustificable $\mathrm{y}$, por lo tanto, discriminatoria?

Antes de intentar aportar alguna luz en torno a este problema, quisiera hacer una precisión y dos acotaciones. La precisión es que con esta pregunta nos estamos adentrando fundamentalmente a un problema de justicia y, por lo tanto, a un problema que tan sólo puede ser resuelto a través del razonamiento práctico. La fórmula clásica "hay que tratar igual lo igual y desigual lo desigual", sin duda, debe constituirse en nuestro punto de partida. Sólo que, como lo apunta Robert Alexy, resulta necesario desechar una comprensión meramente formal de este principio, para adoptar

1 En este sentido Robert Alexy afirma textualmente: "La igualdad de todos con respecto a todas las posiciones jurídicas conduciría no sólo a normas no funcionales, disparatadas e injustas, sino que también eliminaría los presupuestos para el ejercicio de las competencias. Todo elector debería ser también elegido y todo subordinado debería ser también jefe. Todo vendedor tendría no sólo el derecho a que se le pague el precio de venta sino también el deber de pagarlo etcétera". $C f r$. Alexy, Robert, Teoría de los derechos fundamentales, traducción de Ernesto Garzón Valdés, Madrid, Centro de Estudios Constitucionales, 1997. En este mismo sentido Luigi Ferrajoli sostiene que el derecho puede adoptar cuatro posturas distintas ante los conceptos de igualdad y diferencia: la de ser indiferente ante las diferencias, la de diferenciar juradamente las diferencias, la de homologar jurídicamente las diferencias y la de valorar jurídicamente las diferencias. Ferrajoli, Luigi. Derechos y garantías; la ley del más débil, traducción de Perfecto Ibáñez y Andrea Greppi, Madrid, Trottta, 2002. 
una comprensión material. ${ }^{2}$ La perspectiva formalista tan sólo ve en esta fórmula una exigencia de universalización, es decir, que el postulado se cumpla por el mero hecho de otorgar el mismo tratamiento a todos los casos que se coloquen en un supuesto igual. Con ello, un legislador podría llevar a cabo cualquier discriminación sin violarlo, siempre que la proposición jurídica otorgue el mismo trato a personas iguales y el mismo trato desigual a personas que considera se encuentran en un supuesto jurídico distinto del resto. En este sentido, el régimen del apartheid en Sudáfrica cumplió cabalmente con el principio de justicia, pues exigia un trato igual a las personas de piel blanca, al mismo tiempo que establecía un trato desigual pero generalizado a todas las personas de piel negra. ${ }^{3}$ Una perspectiva material, en cambio, integra un tercer elemento en la relación, un elemento que nos sirve de referente para determinar qué aspecto estamos tomando en cuenta para determinar cuándo una persona es igual a otra o para determinar que es desigual a otra. Desde esta perspectiva el problema central de la justicia es, como lo indica Brian Barry, determinar las relaciones de igualdad y diferencia entre las personas, es decir, establecer el criterio o principio que nos permita identificar cuando y en qué aspecto una persona es igual a otra $\mathrm{y}$, por lo tanto, merece ser tratada de manera igual y cuándo y en qué aspecto es desigual a otra y, por lo tanto, exige ser tratada desigualmente. ${ }^{4}$

Ahora bien, el primer problema reside aquí, en que un elemento meramente fáctico para determinar cuándo estamos frente a personas iguales y cuándo frente a personas

2 Cfr. Alexy, Robert, op. cit., nota 1. pp. 387.

3 Otro ejemplo es el caso Pace vs. Alabama de 1883 en el cual la Suprema Corte de los Estados Unidos se negó a declarar la inconstitucionaidad de una ley del estado de Alabama que prohibía las relaciones sexuales interraciales, argumentando que no violaba la equal protection clause debido a que castigaba con el mismo rigor tanto a las personas blancas como a las negras que participaran en este tipo de relaciones. Cfr. Kermit L. Hall, (ed.), The Oxford Guide to United States Supreme Court Decisions, Nueva York, Oxford University Press, 1999.

4 Cfr. Barry, Brian, Teorías de la justicia, traducción de Cecilia Hidalgo, Barcelona, Gedisa, 1995, p. 19. 
desiguales no es suficiente. Pues un hecho irrefutable es que los seres humanos somos al mismo tiempo iguales en uno o varios aspectos y desiguales en otros muchos aspectos. No existen dos personas o situaciones humanas que no sean iguales en un punto $\mathrm{y}$, al mismo tiempo, desiguales en otros. Para establecer una igualdad o una desigualdad normativa, es decir, para poder establecer que un igual debe ser tratado de igual manera y un desigual de desigual manera, tal y como reza la definición aristotélica, es necesario emitir un juicio de valor por el cual se establezca qué característica o situación de un grupo de personas debe ser tomada en cuenta para considerarlos iguales y qué características deben ser relevantes para afirmar que son desiguales. Con ello hemos desplazado el problema a la cuestión de la valoración correcta o, lo que es lo mismo, a la dificil pero ineludible tarea de fundamentar racionalmente los juicios de valor con base en los cuales se establecen diferencias de trato entre las personas.

La primera acotación consiste en que desde la perspectiva de la no discriminación nuestra problemática se reduce significativamente, pues del concepto mismo de no discriminación queda claro que el elemento de comparación, el tertium comparationis de las relaciones de igualdad y desigualdad que aquí nos ocupan, son los derechos y libertades fundamentales de las personas reconocidos por los instrumentos internacionales de los derechos humanos y por las Constituciones democráticas de la gran mayoría de países. La igualdad, como se sabe, es un concepto relacional, es decir, sólo tiene sentido plantearlo en el marco de una relación entre dos o más objetos o personas. Por ello, su problema central no ha consistido tanto en determinar en qué consiste, sino en definir; primero, entre qué o quienes se predicará la igualdad y, segundo, en establecer en relación a qué elemento o factor se juzgará si existe o no la igualdad. ${ }^{5}$ Así, pues, plantear este problema desde la no discri-

5 Véase entre otros a Bobbio, Norberto. "Igualdad y dignidad de los hombres", El tiempo de los derechos, traducción de Rafael de Asís Roig, Madrid, Sistema, 
minación adelanta un buen trecho la discusión al acotar la problemática en determinar cuándo una desigualdad en el goce y ejercicio de los derechos fundamentales de las personas puede ser justificada racionalmente.

La segunda acotación consiste en reducir considerablemente las posibles entidades o instancias que pueden proporcionar un trato desigual, pues aunque del derecho a no ser discriminado se desprenden obligaciones tanto para los particulares, como para los tres poderes del Estado, aquí me centraré exclusivamente en analizar cuándo un trato desigual establecido por una ley constituye un trato discriminatorio. Y de manera aún más específica, bajo qué criterios el juez puede determinar que una distinción en el ejercicio de los derechos fundamentales de las personas hecha por el legislador constituye una discriminación.

\section{PRIMERA VÍA DE SOLUCIÓN}

La primera vía posible para resolver nuestro problema consiste en centrar la atención en las características o condiciones personales, tales como: raza, sexo, idioma, religión, ideología u opinión política, orientación sexual, las capacidades físicas o mentales, el origen nacional o social, posición económica y el nacimiento, con base en las cuales la gran mayoría de instrumentos internacionales y Constituciones prohíben realizar un trato desigual en el ejercicio de los derechos fundamentales. Pues, al parecer, si logramos identificar cuál es el criterio que las unifica estariamos muy cerca de encontrar la razón fundamental por la cual a lo largo de la historia se ha entendido injustificado hacer distinciones con base en estos motivos prohibidos.

A primera vista, podría parecer que es indebido hacer una distinción con base en estas características por el hecho de que la persona nace con ellas, en el sentido de que

1990, pp. 37-53; y Ruiz Miguel, Alfonso, "Sobre el concepto de igualdad", en Carbonell, Miguel (comp.), El principio constitucional de igualdad. Lecturas de introducción, México, Comisión Nacional de los Derechos Humanos, 2003, pp. 31-67. 
no son elegidas o forjadas por la persona y, por lo tanto, la persona no puede hacerse responsable de ellas. Así parecería que se está siguiendo el razonamiento del artículo 6o. de la Declaración francesa de los Derechos del Hombre y del Ciudadano del 26 de agosto de 1978, cuando al consagrar la igualdad de todos los hombres ante la ley, puntualizaba que la única distinción admisible entre los hombres era la derivada de sus virtudes y sus talentos. ${ }^{6}$ Este criterio podría ser válido para las distinciones hechas con base en características tales como el sexo, la raza, las capacidades fisicas, pero, sin duda, no podría aplicarse a otros supuestos como la religión, la ideología, la situación social, etcétera. Pues, sin duda, resulta tan injusto distinguir a alguien en el ejercicio de sus derechos por la religión que profesa o las ideas políticas que sostiene como distinguirlo por su color de piel o su origen étnico, al igual que resulta injustificado restringir a una mujer embarazada su derecho al trabajo, aun y cuando ella haya decidido libremente embarazarse. Pero, además, éste argumento, que justifica las distinciones de acuerdo con la responsabilidad de cada persona en la configuración de su situación, podría esgrimirse para justificar la discriminación motivada por la condición social de la persona. Entendiendo que éstas son las únicas responsables de su condición social y económica, sin considerar que en muchas ocasiones las diferencias entre las personas son originadas por factores sociales que dificilmente pueden ser controlados por las personas y en los cuales tienen poca responsabilidad. ${ }^{7}$

6 Artículo 6o. de la Declaración de Derechos del Hombre y del Ciudadano: "La Ley es la expresión de la voluntad general. Todos los ciudadanos tienen el derecho de participar personalmente o por medio de sus representantes en su formación. Debe ser la misma para todos, tanto si protege como si castiga. Todos los ciudadanos, al ser iguales ante ella, son igualmente admisibles a todas las dignidades, puestos y empleos públicos, según su capacidad y sin otra distinción que la de sus virtudes y la de sus talentos".

7 John Rawls presenta este argumento de la siguiente manera "Es justo que los individuos tengan porciones desiguales de bienes sociales, en la medida en que dichas desigualdades hayan sido ganadas y merecidas por los individuos, esto es, en la media en que sean el resultado de sus acciones y decisiones. En cambio es in- 
Otro posible criterio es el de la no relevancia, en el cual se sostiene que ninguna de las características antes mencionadas son los suficientemente determinantes o relevantes como para negar o restringir los derechos fundamentales de las personas. ¿Qué relevancia puede tener, por ejemplo, el origen étnico de una persona en relación con su derecho a la libertad de expresión o sus creencias religiosas en relación con sus derechos a la educación? Aunque este criterio tiene una aplicación más amplia que el criterio de responsabilidad parecería que por su generalidad nos serviría como un criterio indicador, pero no como un criterio concluyente de una distinción injustificada. Pues si contextualizamos más podriamos encontrar algunos casos concretos en los cuales ciertas características personales son relevantes para poder gozar o ejercer algunos derechos fundamentales; tal es el caso de una determinada edad para ejercer el derecho a votar o el de ser nacional de un país para ejercer determinados cargos públicos.

Así, pues, me parece que realmente no existe un único criterio común capaz de aglutinar todas las características por las cuales se considera injustificado hacer una distinción. Esto se debe a que la manera en que la lista de estos criterios fue conformándose en la historia no fue a través de una razonamiento abstracto ni a partir de un solo principio capaz de ir determinando qué características personales deben ser tomados en cuenta para hacer distinciones en cuanto a la titularidad y ejercicio de los derechos fundamentales y cuáles no, sino que realmente, la conformación de este catálogo de motivos prohibidos se ha forjado a tra-

justo que algunos individuos acaben siendo desfavorecidos o privilegiados por diferencias arbitrarias y no merecidas en sus circunstancias reales". Cómo es sabido Rawls critica este argumento en base a que no solo los factores sociales, sino también los factores naturales, como la capacidad intelectual con la cual cada un nace o la familia y la posición social de la que la persona disfruta en su infancia, son determinantes de las desigualdades que existen entre las personas. Frente a este problema Rawls presentará su principio de la diferencia, por el cuál sostiene que las diferencias entre las personas sólo pueden ser justificadas cuando éstas resultan ventajosas para aquellos menos afortunados de la sociedad. Cfr. Rawls, John, Teoría de la justicia, traducción de Maria Dolores González, México, Fondo de Cultura Económica, 1979, pp. 95-105. 
vés del tiempo como resultado de la lucha de grupos específicos que han logrado reivindicar una igualdad en el ejercicio de sus derechos. Así, la prohibición de discriminar por motivos de género, de religión, de raza, de origen étnico, edad o nacionalidad, ha sido el resultado de la lucha por la igualdad de los derechos de las mujeres, de las minorias religiosas, raciales y étnicas, de los niños y, actualmente, de la todavía en litigio lucha por los derechos de los migrantes.

Es por ello, también, que ningún instrumento jurídico considera que la enumeración de estas características sea una lista cerrada e inmutable, por el contrario, se deja abierta para que sean los jueces los que, teniendo en cuenta las nuevas necesidades sociales que surgen, así como la siempre en evolución y cambiante conciencia moral de la sociedad, vayan determinando nuevas características con base en los cuales se prohíbe dar un trato desigual. ${ }^{8}$ Así, por ejemplo, mientras el proyecto de Constitución europea incluye entre su lista de motivos prohibidos las características genéticas de las personas, ${ }^{9}$ el Comité de Derechos Humanos de la ONU ha ampliado el catálogo contenido en el artículo 26 del Pacto Internacional de Derechos Civiles y Políticos integrando cuestiones como: estatus marital o civil (Danning vs. The Netherlands (602(94), el lugar de residencia (Lindgren et al., vs. Sweden (298-299/88), la distinción entre hijo fuera y dentro del matrimonio (Oulajin \& Kaiss vs. The Netherlands

8 La Corte Europea de Derechos Humanos ha manifestado que aunque en épocas pasadas un determinado criterio se consideraba justificado para hacer algún tipo de distinción, la conciencia moral de las sociedades se encuentra en constante evolución por lo que resulta necesario verificar si los mismos criterios hoy en día pueden ser justificados o no. Veáse como ejemplo el caso Inze vs. Austria del 28 de octubre de 1987, en el cual se establece que ya no se puede justificar hacer distinciones entre las personas por el hecho de haber nacido fuera o dentro del matrimonio. http:// cmiskp.echr.coe.int/tkp197/ portal.asp?sessionId $=748599 \&$ skin $=h u$ doc-en\&action $=$ request.

9 El Artículo II-81.1 del Proyecto de Constitución Europea establece expresamente: "Se prohíbe toda discriminación, y, en particular, la ejercida por razón de sexo, raza, color, orígenes étnicos o sociales, características genéticas, lengua, religión o convicciones, opiniones políticas o de cualquier otro tipo, pertenencia a una minoría nacional, patrimonio, nacimiento, discapacidad, edad u orientación sexual". 
(406, 426/90), las personas empleadas y desempleadas (Cavalcanti Araujo-Jogens vs. The Netherlands (419/90) y la orientación sexual (Toonen $v s$. Australia (488/92). ${ }^{10}$

Otra razón por la cual me parece que no es posible deducir los criterios bajo los cuales se puede establecer que una distinción hecha por una ley debe considerarse racionalmente injustificable de las características mencionadas, reside en la manera en que ésta ha funcionado en la práctica jurisdiccional en torno a la no discriminación consiste en tomarlas como criterios por los que sólo prima facie estamos frente a una distinción injustificable, pues aunque una ley haya hecho una distinción con base en estos criterios es posible que el juzgador encuentre razones suficientes que justifiquen dicha distinción, lo cual implica que las distinciones hechas con base en las mencionadas características personales no deben ser consideradas automáticamente discriminatorias. Esto es lo que en la jurisprudencia de la Suprema Corte de los Estados Unidos de América se ha denominado la prueba del strict scrutiny, la cual consiste en considerar como sospechosa toda distinción realizada por el legislador que esté basada en criterios como el sexo o la raza, por lo cual se exige al juez que analicé detenidamente cada uno de los argumentos vertidos y de los fines que se persigue con esa distinción para determinar si existen realmente o no razones suficientes que la justifique. ${ }^{11}$ Por su puesto, el caso paradigmático de esta problemática la encontramos en las acciones afirmativas, las cuales realizan una distinción en derechos basada en alguna de las características personales analizadas que pretende justificarse en orden a la realización de ciertos fines, tales como: la compensación de una discriminación histórica, la subrrepresentación de un grupo social en las distintas esferas de

10 Véase Joseph, Sarah et al., The International Convenant on Civil and Political Rights; Cases, Materials and Commentary, Nueva York, Oxford University Press, 2000.

11 Sobre la Jurisprudencia de la Suprema Corte de los Estados Unidos a este respecto véase: Dworkin, Ronald, Sovereign Virtue; The Theory and Practice of Equality, Cambridge-Massachussets, Harvard University Press, 2000. 
la vida pública o, en general, promover una igualdad sustancial entre los miembros de la sociedad. ${ }^{12}$

\section{SEGUNDA VÍA DE SOLUCIÓN}

Otra vía para detectar los criterios bajo los cuales se puede justificar una distinción realizada por una ley consiste en acudir a la jurisprudencia que en años recientes han desarrollado los tribunales constitucionales de algunos países, así como los tribunales internacionales y regionales de derechos humanos en torno a los principios de igualdad y no discriminación. Aunque, como es obvio, en la respuesta de cada tribunal a esta problemática se imprime el sello de la cultura jurídica a la que pertenece, en general llama la atención que exista tanto un avance paralelo, como una confluencia importante en los criterios elegidos. ${ }^{13}$ En términos generales, y a pesar de que algunos tribunales empleen otros términos como el de arbitrariedad ${ }^{14}$ en el caso del Tribunal Constitucional alemán o el del "compelling interest"

12 Sobre este tema véase: Rosenfeld, Michel. Affirmative Actino and Justice; A Philosophical and Constitucional Inquiry, New Haven, Yale University, 1991; Bossuyt, Marc, "El concepto y la práctica de la acción afirmativa", Informe final presentado de conformidad con la resolución 1998/ 5 de la Subcomisión de Promoción y Protección de los Derechos Humanos, Naciones Unidas, E/CN.4/Sub.2/2002/21, del 17 de junio de 2002; y Gimnénez Gluck, David, Una manifestación polémica del principio de igualdad: acciones positivas moderadas y medidas de discriminación inversa, Valencia, Tirant lo Blanch, 1999.

13 La razón de esta confluencia se debe a la influencia que ha tenido la Corte Europea de Derechos Humanos tanto en otros tribunales regionales de derechos humanos, como en algunos de los tribunales constitucionales de los Estados europeos y latinoamericanos. En el caso de la Suprema Corte de los Estados Unidos el desarrollo jurisprudencial en torno a la XIV enmienda de la Constitución ha sido mucho más autónomo que en el resto de los países, constituyendo una jurisprudencia muy rica, pero también, compleja debido a los constantes cambios de posiciones que la interpretación de la "equal protection cluase" ha sufrido durante los últimos 150 años.

14 En este sentido el Tribunal Constitucional Federal alemán sostiene que: "La máxima de la igualdad es violada cuando para la diferenciación legal o para el tratamiento legal igual no es posible encontrar una razón razonable, que surja de la naturaleza de la cosas o que, de alguna otra forma, sea concretamente comprensible, es decir, cuando las disposiciones tiene que ser calificada de arbitraria”, p. 391 BVerfGE 1, 14 (52) jurisprudencia permanente. 
en el caso de la Suprema Corte de los Estados Unidos, bajo la influencia de la Corte Europea de Derechos Humanos la gran mayoría de los tribunales nacionales han adoptado el criterio general de que "una diferencia de trato es discriminatoria si no cuenta con una justificación racional y objetiva". 15

Ahora bien, la pregunta obligada es ¿cómo han definido o en qué términos han entendido que estamos frente a una justificación racional y objetiva? Frente a esta pregunta los tribunales han formulado diversos criterios, todos ellos, por supuesto, toman muy en cuenta los casos concretos que han tenido que resolver, así como la tradición jurídica a la que pertenecen y, sobre todo, las concepciones morales que rigen sus sociedades y de las cuales están impregnadas los instrumentos jurídicos que toman como referente. Sin embargo, me parece que la pluralidad de criterios puede reducirse a dos criterios amplios: primero, si la distinción y la ley en la cual se contiene persiguen un fin legítimo y, segundo, si existe una relación de proporcionalidad entre el fin que se persigue con la distinción y los medios que se emplean para lograrla. ${ }^{16}$ A continuación analizaré muy bre-

15 La Corte Europea de Derechos Humanos expresamente sostiene el siguiente criterio: "a difference of treatment is discriminatory if it has no objective and reasonable justification, that is, if it does not pursue a legitimate aim or if there is not a reasonable relationship of proportionality between the means employed and the aim sought to be realized". Cfr. Case of Sidabras and Dziautas vs. Lithuania, del 27 de julio de 2004, p. 17.

16 En el caso de la Suprema Corte de Justicia de la Nación, a partir de la incorporación del ministro Cossió, se han introducido criterios similares para determinar cuando una distinción puede ser juzgada. Según la Corte se tienen que tomar en cuenta los tres siguientes criterios: 1) la distinción legislativa debe obedecer a una finalidad objetiva constitucionalmente válida. Es decir, el legislador no puede establecer distinciones arbitrariamente sino que éstas deben de atender a un objetivo que sea válido en referencia al marco constitucional; 2) debe existir una adecuación racional entre la distinción introducida y el fin que se persigue. Se debe fundamentar racional y objetivamente que existen probabilidades serias de que mediante la distinción realizada se consiga el fin que se persigue; 3) las distinciones introducidas deben ser proporcionales en relación con los derechos que se ponen en riesgo con motivo de la distinción. Se exige un análisis objetivo sobre la pertinencia de la distinción a la luz de otros derechos constitucionalmente protegidos. Cfr. Tesis Aislada, Semanario Judicial de la Federación y su Gaceta, Primera Sala, t. XX, diciembre de 2004, tesis 1a. CXXXII/2004, p. 362. 
vemente algunos casos concretos con el fin de contextualizar y profundizar en estos criterios.

\section{Fin legitimo de la distinción}

El criterio del fin legítimo opera mediante el desplazamiento de la actividad argumentativa hacia la cuestión del fin que se pretende alcanzar con la desigualdad de trato. Con ello, se pone en la balanza, por una parte, el principio de igualdad en derechos $\mathrm{y}$, por otra parte, los principios o valores que intentan alcanzarse o resguardarse con la distinción. Lo que se exige al juzgador es un juicio de ponderación entre dos principios que en el caso concreto se presentan como antagónicos, pero no del todo excluyentes. ${ }^{17} \mathrm{La}$ legitimidad del fin, por lo tanto, no se deduce en abstracto, sino en estrecha relación con el principio de igualdad en derechos. Así, pues no se requiere tan sólo que el fin, o mejor dicho, los valores o principios cuya realización se constituyen en el fin y motivo último de la distinción, se encuentren reconocidos por el orden jurídico que sirve de marco en la discusión o, incluso, el que sean propugnados por la mayoría democrática, sino que, además, se requiere que tengan un peso normativo de tal magnitud que con base en ellos se justifique quebrantar el principio de igualdad en derechos.

El problema más acuciante reside en que existe una pluralidad de fines de muy diversa naturaleza que pueden entrar en el juicio de ponderación. Desde conceptos tan abstractos como el de interés nacional, utilidad pública, seguridad nacional, buenas costumbres, moral pública, hasta otros principios o conceptos más particulares, pero no por ello más fáciles de definir, como el pleno empleo, el interés del menor, la protección de la familia y, en el caso de las acciones afirmativas, la igualdad de oportunidades en el ejercicio de los derechos. Ante la vaguedad de estos conceptos los juzgadores deben de tener especial cuidado en detectar si

17 Sobre el juicio de ponderación véase: Prieto Sanchís, Luis, Justicia constitucional y derechos fundamentales, Madrid, Trotta, 2003, pp. 175-217. 
detrás de ellos no se esconde algún prejuicio discriminatorio inconfesable.

Veamos algunos ejemplos de la problemática que entraña determinar la objetividad y racionalidad de ciertas distinciones con base en los fines que éstas persiguen.

Un caso paradigmático en este sentido es el caso Hirabayashi vs. United States, resuelto por la Suprema Corte de los Estados Unidos en 1943. En él se planteó la cuestión de si las medidas legislativas implementadas por el gobierno de los Estados Unidos, que exigían la reubicación y concentración en zonas militares de seguridad de todos los ciudadanos americanos descendientes de japoneses que vivieran en la Costa Este, eran discriminatorias o no. Por unanimidad la Corte resolvió que aunque en efecto dichas medidas establecían un trato desigual entre los ciudadanos norteamericanos basado en el origen racial, dicha distinción quedaba justificada plenamente debido a una cuestión de "defensa nacional", pues existía un temor "fundado" de una posible invasión militar de Japón en las costas de California y de que los americanos descendientes de japoneses pudieran apoyar esa invasión por medio de boicots y sabotajes. ${ }^{18}$

Otro caso en el que se justifica una distinción de derechos con base en el fin que persigue la ley es el relativo a la legislación laboral española, que establecía la edad de sesenta años como jubilación forzosa. El Tribunal Constitucional consideró que aunque de hecho se trataba de una distinción que tenía como consecuencias la restricción de derechos de un grupo muy importante de la sociedad, dicha distinción se encontraba justificada en virtud de que perseguía dos fines legítimos específicos: permitir el ingreso de personas jóvenes al mercado laboral y poner en práctica una política de pleno empleo. Además que se encontraba respaldada por principios y valores asumidos constitucionalmente, como son la solidaridad, la igualdad real y efecti-

18 Hirabayashi $v$. United States (21/06/1943). 
va y la participación de todos en la vida económica del país. ${ }^{19}$

Otro caso en que se resolvió que existía un fin legítimo es el caso Singh Bhinder vs. Canda, resuelto por el Comité de Derechos Humanos de las Naciones Unidas. El Comité resolvió que una norma laboral que exigía que todos los trabajadores de la construcción utilizaran casco en el horario de trabajo constituía una discriminación indirecta, debido no a la norma en sí misma, que sin duda era neutral y no era en sí misma discriminatoria, sino en cuanto colocaba a todos los miembros de la religión Sihj, a los cuales su religión les exige llevar turbante durante el dia, en una situación de desventaja respecto del resto de los trabajadores. Sin embargo, en el caso concreto el Comité falló a favor de Canadá al entender que el fin que se buscaba con la ley, el cual era salvaguardar la integridad física de los trabajadores de la construcción, era perfectamente legítimo. ${ }^{20}$

Por el contrario, la Corte Europea de Derechos Humanos ha resuelto varios casos en los que se considera ilegitimo e injustificable el fin que se persigue con el trato desigual. En la Gran Bretaña la legislación migratoria hacía una distinción entre las esposas y los esposos de los migrantes, pues mientras permitía que los hombres migrantes solicitaran la legalización de sus esposas, prohibía a las mujeres migrantes hacer lo mismo en relación con sus maridos. El argumento en el que se basaba esta distinción consistía en que mientras las esposas de los inmigrantes al llegar a Inglaterra se integraban a las labores del hogar, los esposos de las inmigrantes llegaban a buscar trabajo provocando tensión social debido a las grandes tasas de desempleo que afectan a los ciudadanos ingleses. La Corte resolvió que este argu-

19 Cfr. STC 22/1981. Para un análisis de la labor del Tribunal Constitucional Español en torno al derecho a la no discriminación de las mujeres véase: Rey Martínez, Fernando, El derecho fundamental a no ser discriminado por razón de sexo, México, Conapred, 2005.

20 Cfr. Singh Bhinder vs. Canadá $(208 / 86)$ Josepch, Sarah. Shultz, Jenny \& Castan, Melissa, The International Covenant on Civil and Political Rights, Nueva York, Oxford University Press, 2000, p. 530. 
mento no era ni objetivo ni razonable, debido a que las estadísticas de empleo en Inglaterra indican que los hombres y las mujeres inmigrantes tiene las mismas posibilidades de integrarse al mercado laboral y que, incluso, los hombres inmigrantes no sólo no restan fuentes de trabajo, sino, que, por lo general, se autoemplean creando nuevos empleos. ${ }^{21}$

Otro caso es el de una mujer turca que alegaba que el Código Civil de su país la discriminaba en tanto exigía que la mujer adoptara el apellido del marido y abandonara el suyo al momento de contraer matrimonio. La Corte resolvió que el fin de preservar la unidad familiar, alegado por el Estado de Turquía para justificar la distinción del Código Civil, realmente no constituía una razón suficiente para legitimar una distinción basada en el sexo de las personas, pues realmente el que la mujer pudiera conservar su propio apellido después de casarse, o bien, el que la legislación previera la posibilidad de que los cónyuges eligieran libremente el apellido de la familia, en nada mermaba la unidad familiar. 22

Otros caso más debatible es el caso L. y V vs. Austria de 2003 en el que la Corte tuvo que analizar si un artículo del Código Penal austriaco resultaba discriminatorio al penalizar, por un parte, las relaciones homosexuales consentidas entre un adulto y un menor de entre 14 y 18 años, mientras que, por otra parte, no prohíbe las relaciones heterosexuales entre un adulto y un mayor de 14 años. El Estado austriaco alegó que el fin de la disposición era el proteger el desenvolvimiento sexual de los adolescentes, a lo cual la Corte respondió que la mayoría de los estudios científicos demostraban que la definición de la orientación sexual se realiza durante la pubertad, por lo cual el temor de que un adulto pudiera influir en la orientación sexual de los mayo-

21 Abdulaziz, Cabales and Balkandali vs Great Britain. http://cmiskp.echr. coe.int $/$ tkp 197/view.asp?item=1\&portal=hbkm\&action $=h$ tml\&highlight=abdulaziz\% 2C\%20\%7C\%20cabales\%20\%7C\%20balkandali\&sessionid=6400986\&skin=hudoc-en.

22 Unal Tekeli vs Turkey (2004). http://cmiskp.echr.coe.int/tkp197/view.asp?i tem $=1$ \&portal $=h b k m \&$ action $=h t m l \& h i g h l i g h t=$ unal\%20\%7C\%20tekeli\&sessionid $=64$ 00998\&skin=hudoc-en. 
res de 14 años era infundado. Con base en este razonamiento y tomando en cuanta de que en la gran mayoria de las legislaciones de los Estados pertenecientes al Consejo de Europa no hacen una distinción en la edad mínima para tener relaciones sexuales consentidas con personas adultas entre homosexuales y heterosexuales, la Corte decidió que el fin de proteger el desenvolvimiento sexual de los adolescentes no justificaba plenamente la distinción realizada por el Código Penal austriaco. ${ }^{23}$

\section{Relación de proporcionalidad}

El criterio de proporcionalidad que los tribunales también emplean apela a la relación entre los medios empleados para establecer una desigualdad de trato y el fin que se persigue con ella. Por ello constituye un filtro más por el que debe pasar toda norma que rompa con el principio de la igualdad en derechos, pues no basta sólo con que se legitime el fin, sino, además, de que los medios a través de los cuales se establece la distinción y, sobre todo, las consecuencias que se derivan de ella, no sean evidentemente desproporcionados a los beneficios que se pretenden alcanzar con la distinción. Por supuesto, aquí también se trata de un juicio de ponderación, no ya entre dos principios en colisión, sino entre los beneficios y desventajas que puede acarrear una distinción y las ventajas que se pretenden con el fin por el cual se justifica el trato desigual.

Un caso que puede servir de ejemplo para aclarar este criterio es el de dos servidores públicos del gobierno Lituano, los cuales con base en una ley emitida con posterioridad al desmembramiento de la Unión Soviética, fueron separados de su cargo por haber pertenecido durante el régimen comunista a la KGB. La Corte Europea de Dere-

23 L and V v Austira (2003) http://cmiskp.echr.coe.int/tkp197/view.asp?item= $5 \&$ portal $=h b k m \&$ action $=h$ tml\&highlight $=$ austria $\% 20 \% 7 C \% 2014+8 \&$ sessionid $=6400$ 998\&skin=hudoc-en. 
chos Humanos calificó como objetivo y racionalmente justificable el argumento dado por el gobierno lituano, consistente en que la medida tenía como fin evitar que en el servicio público trabajara gente que por sus labores anteriores al servicio de los instrumentos de control y espionaje de la Unión Soviética había demostrado no ser fiel al gobierno democrático vigente. Sin embargo, consideró que los efectos de la medida eran desproporcionados a sus fines dado que no sólo no se les permitía laborar en el servicio público, sino que, además, se les impedia obtener un trabajo en la iniciativa privada. ${ }^{24}$

En esta mismo orden de ideas la Suprema Corte de los Estados Unidos ha introducido el criterio denominado compelling interest que sirve para valorar la constitucionalidad de las acciones afirmativas que establecen un trato preferencial a favor de las minorias raciales con el fin de remediar una situación anterior de discriminación en el ejercicio de sus derechos. A través de este criterio se exige que los jueces además de analizar la legitimidad del fin que se pretende alcanzar con la acción afirmativa tomen en cuenta otros elementos, tales como: que no existan otra alternativas jurídicas para conseguir el mismo fin, que exista una necesidad probada de la urgencia de tal medida, la posibilidad real de que el trato diferencial tenga éxito en cuanto al fin que persigue y el efecto que la medida puede provocar en terceras personas, especialmente en las personas pertenecientes a la mayoría racial. ${ }^{25}$

\section{CRITERIO MATERIAL DE VALORACIÓN}

Sin duda, los dos anteriores criterios analizados son sumamente útiles para determinar cuándo estamos en presencia de una distinción objetiva y racional y cuando no,

24 Véase el caso Case of Sidabras and Dziautas $v$. Lithuania del 27 de julio de 2004. Cfr. http://cmiskp.echr.coe.int/tkp197/portal.asp?sessionId=748890\&skin= hudoc-en\&action=request.

25 Cfr. Richmond v. J.A. Croson Co. 488 U.S. 469 (1989). 
sin embargo, de los ejemplos analizados podemos intuir con facilidad que aunque estos criterios tienen la virtud de conducir y acotar ligeramente el campo argumentativo, no son en modo alguno determinantes ni, desde mi punto de vista, suficientes. La razón de ello es muy sencilla y consiste en que tanto el criterio del fin legítimo como el de proporcionalidad exigen a su vez un tercer criterio de valoración. Si se pretende que el tipo de racionalidad empleada para determinar cuándo un trato desigual se encuentra justificado, no sea sólo el de la racionalidad instrumental, es decir, la racionalidad que sólo es capaz de elegir los medios más adecuados para alcanzar un fin dado y requerimos emplear lo que Max Weber ha llamado racionalidad de valores "Wertrationalitat", ${ }^{26}$ a través de la cual además podemos elegir, de entre la pluralidad de fines y valores, el fin correcto para guiar nuestra conducta, es necesario que introduzcamos un tercer criterio que nos sirva de referente para discernir cuándo un fin es legítimo y cuándo un medio empleado resulta desproporcionado.

Los tribunales se han percatado de esta necesidad y han tratado de reconducir los criterios del fin legítimo y de proporcionalidad a un tercer criterio de valoración. En el caso de los tribunales constitucionales español y alemán la remisión ha sido a los principios y valores contenidos en sus respectivos textos constitucionales, el Comité de Derechos Humanos ha determinado que los fines que justifiquen un trato discriminatorio tiene que estar en plena sintonía con el resto de valores y principios contenidos en el Pacto Internacional de Derechos Civiles y Políticos, la Corte Europea de Derechos Humanos en repetidas ocasiones apela al consenso alcanzado en los diversos órdenes jurídicos de los Estados europeos para determinar la legitimidad o ilegitimidad del fin, mientras que la Corte Interamericana de Dere-

26 Weber, Max, La ciencia como profesión; la politica como profesión, traducción de Joaquín Abellan, Madrid, Espasa-Calpe, 1992. 
chos Humanos ha apelado al concepto de dignidad humana como criterio último de valoración. ${ }^{27}$

La coincidencia más notoria que existe entre la manera de proceder de los tribunales es que todos ellos remiten a un criterio material de valoración y no a otro criterio formal que nos dejaría en la misma situación que los criterios del fin y de la proporcionalidad. En este mismo sentido Robert Alexy sostiene que en último término el problema de determinar la racionalidad de un trato desigual nos remite a un concepto específico de justicia, así como a un concepto de derecho y de sociedad. ${ }^{28}$ Por ello, sería falso afirmar que el criterio de valoración debería ser neutral a todas las concepciones del mundo y de la vida que existen en la sociedad, por el contrario, los criterios a los que los tribunales nos remiten hunden sus raíces en una concepción del mundo y de la vida determinada, la cual ha sido proyectada en los instrumentos internacionales de derechos humanos, así como en las Constituciones democráticas de occidente y se arroga a sí misma un cierto grado de universalidad.

Ahora bien, me parece que además de comportar una dimensión material, el criterio debe contener dos notas fundamentales. Primera, que sea lo suficientemente amplio y flexible como para no constreñir demasiado la libertad argumentativa de los juzgadores y permitirles que sea aplicado a cualquier caso concreto en el que se cuestione la legitimidad de quebrar el principio de igualdad de derechos. Y segunda, que exprese un contenido ético mínimo, pero irreductible, que sirva de pauta última para determinar con cierta precisión si un trato desigual puede justificarse o no.

Tomando en cuenta estos elementos, el criterio que propongo para complementar los criterios del fin legítimo y el de la proporcionalidad de los medios es el siguiente: una distinción en el ejercicio de los derechos de las personas se entenderá como discriminatoria cuando coloque a un determinado grupo de personas en una situación tal que en la

27 Cfr. Opinión Consultiva OC-4/84, del 19 de enero de 1984.

28 Alexy, Robert, op. cit., nota 1, pp. 395. 
práctica se vea restringido sustancialmente las posibilidades que tienen de autodesarrollarse y de autodeterminarse, abriendo la posibilidad de que otras personas obtengan alguna ventaja de ello.

En realidad los conceptos centrales de este criterio: el autodesarrollo y la autodeterminación, desde mi punto de vista, constituyen una expresión del concepto más amplio, y, también, más complejo de la dignidad de la persona humana. La razón por la cual encuentro necesario introducir este concepto en el análisis se debe a que desde mi punto de vista constituye el fundamento filosófico con base en el cual se deben prohibir todas las formas de discriminación. El acto discriminatorio consiste esencialmente en el menosprecio del otro, en la infravaloración que una persona hace de otra por motivo de alguna condición o característica personal. En la discriminación sucede, además, que el juicio de valor y la razón por la que tomamos sólo una característica de la persona van precedidas de un prejuicio erróneo que guardamos en relación con un grupo humano con el cual identificamos a la persona. Así pues, no tomar a la persona por sí misma, sino tan sólo una parte de ella desde un enfoque totalmente subjetivo implica, ante todo, tratar a la persona como algo y no como alguien. La discriminación muestra la incapacidad del hombre de reconocer al otro como semejante, es decir, como alguien quien comparte el mismo valor que nosotros mismos consideramos tener al presentarnos como personas. ${ }^{29}$ Discriminar, en sintesis, implica degradar el valor de la persona. Trazar un abismo entre el yo y el otro que acaba imposibilitando la capacidad

29 En el preámbulo de la Declaración y Programa de Acción de la Conferencia Mundial contra el Racismo, la Discriminación Racial, la Xenofobia y las formas conexas de Intolerancia, realizada en Durban, Sudáfrica en 2001, se reconoce expresamente que la discriminación vulnera la dignidad humana: "Afirmando que el racismo, la discriminación racial, la xenofobia y las formas conexas de intolerancia, cuando equivalen a racismo y discriminación racial, constituyen graves violaciones de todos los derechos humanos y obstáculos al pleno disfrute de esos derechos, niegan la verdad evidente de que todos los seres nacen libres e iguales en dignidad y en derechos,...". Cfr. Principales instrumentos internacionales sobre discriminación y racismo, México, CNDH, 2004, pp. 221-311, esp. p. 224. 
que tenemos los hombres de reconocernos como iguales, a la vez, que se niega la libertad de cada uno de expresar su identidad de forma diversa a la de los demás. ${ }^{30}$

Ahora bien, me parece que existen dos objeciones que se pueden hacer a esta propuesta. La primera consiste en desestimar el concepto de dignidad humana por entender que se encuentra imbuido y altamente cargado de una concepción religiosa del hombre. Sin duda, si analizamos el génesis de este concepto no podemos negar que sus raíces implican un conjunto de creencias religiosas que convergen en comprender al hombre como algo sagrado. Sin embargo, me parece que ante esta objeción podemos retomar la interpretación no trascendente o secularizada que Kant ha hecho de la dignidad humana, al comprender que el hombre existe como un fin en sí mismo y no sólo como un medio. ${ }^{31}$ La segunda objeción consiste en afirmar que la dignidad humana es un concepto demasiado oscuro y ambiguo, el cual pude ser utilizado para defender posturas morales diversas e, incluso, contradictorias. Sin embargo, me parece que aunque, sin duda, la dignidad humana es un concepto complejo y, si se me apura, incluso incomesurable, esto no quiere decir que de él no se puedan desprender al menos dos exigencias éticas, claras y objetivas, que pueden servirnos de criterio para determinar cuando un trato desigual es injustificado.

La primera de ellas es la inalienabilidad de la vida humana, la cual implica que la persona humana vale en sí misma y, por lo tanto, nadie puede determinar su valor, o en

30 Esta misma idea parece defender Michael Ignatieff cuando afirma que el progreso moral pude ser medido a través de la intuición de que cada uno de los individuos que componen la especie humana merece una idéntica consideración moral. Cfr. Ignatieff, Michael, Los derechos humanos como politica e idolatría, traducción de Francisco Beltrán Adell, Barcelona, Paidós, 2003, p. 30.

31 En este sentido afirma Kant textualmente: Ahora yo digo que el hombre y, en general, todo ser racional, existe como fin en sí mismo y no sólo como medio para cualesquiera usos de esta o aquella voluntad, y debe ser considerado siempre al mismo tiempo como fin en todas sus acciones, no sólo las dirigidas a sí mismo sino las dirigidas también a los demás seres racionales". Cfr. Kant, Immanuel, Fundamentación de la metafísica de las costumbres, traducción de Luis Martínez de Velasco, Madrid, Espasa, 1999, p. 102. 
otras palabras, fijarle un precio. De hecho esto es lo que para Kant distingue a las personas de las cosas, pues en sus propias palabras: "aquello que tiene precio puede ser sustituido por algo equivalente; en cambio, lo que se halla por encima de todo precio $\mathrm{y}$, por tanto, no admite nada equivalente, eso tiene dignidad". ${ }^{32}$ Cuando una desigualdad de trato coloca al hombre en una situación tal que le es negado su valor intrínseco al grado que su libertad, su vida, su honor o su cuerpo son susceptibles de traducirse en pesos y centavos, se vulnera irremediablemente su dignidad. El resultado de este proceso es, simple y sencillamente, la cosificación de la persona, reduciéndolo a la voluntad y poder adquisitivo de los más poderosos.

La segunda exigencia ética es la ininstrumentabilidad de la persona. La dignidad exige la irreductibilidad de la persona, es decir, que su valor no puede ser reducido o supeditado a otra instancia bajo ningún concepto. Al compartir todos los hombres la misma dignidad, comparten también igual valor. En otras palabras, debido a que ningún ser humano - no obstante su sabiduria, su riqueza, su capacidad de mando, su belleza física etcétera- vale más que otro, nadie puede someter a otra persona a sus intereses o a sus fines. Como tampoco ninguna persona, por más pequeña e indefensa que ésta sea, puede ser sacrificada en función de conceptos tales como: el progreso científico, el desarrollo económico, el interés de la nación, la lucha contra el terrorismo o, incluso, términos como el bien común -el cual pierde su sentido originario sino es acompañado del bien personal de todos y cada uno de los miembros de la comunidad-. Lo contrario implica reducir a la persona humana a un mero instrumento, esto es, mediatizarla al no ser respetada como un fin en sí misma. La instrumentalización del hombre implica relegar la comprensión fundamental de que cada hombre es único e irrepetible y, por lo tanto, insustituible, para adoptar una postura vital que entiende a los 
demás cómo seres genéricos y contingentes, y, por lo tanto, reemplazables.

A mi juicio estas dos exigencias éticas coinciden, sin que sea necesario forzarlas demasiado con los conceptos de auto desarrollo y autodeterminación que empleamos para construir el criterio propuesto. Para señalar el vínculo que existe entre estos conceptos acudiré al desarrollo que de ellos hace Iris Marion Young a través de las figuras de dominación y opresión. ${ }^{33}$

Para esta autora norteamericana en una sociedad afectada por una enorme desigualdad de oportunidades, el paradigma distributivo de la teoría de la justicia contemporánea resulta insuficiente por dos razones: porque generalmente ignora el contexto institucional que a menudo contribuye a determinar los modelos de distribución ${ }^{34}$ y porque al centrar el problema de la distribución en bienes susceptibles de ser valorados económicamente sólo toma en cuenta lo que las personas tienen y no lo que las personas hacen o son. Ante ello, propone que un concepto de justicia adecuado a este tipo de sociedades debe partir de los conceptos de opresión y dominación. Para Young el concepto de opresión se refiere al conjunto de trabas institucionales que impiden a una persona o a un grupo de personas autodesarrollarse. La estructura social está dispuesta de tal manera que sistemáticamente anula la capacidad que tienen ciertas personas para potenciar sus habilidades y facultades personales, así como de interactuar libremente con los demás expresando sus necesidades, pensamientos y sentimientos. Por otra parte, bajo el concepto de dominación entiende el conjunto de trabas institucionales que impiden que una persona se autodetermine, es decir, que elija libremente los fines

33 Véase: Young, Marion Iris, La justicia y la politica de la diferencia, trad. Silvina Álvarez, Valencia, Ediciones Cátedra, 2000.

34 Por contexto institucional Iris Marion Young entiende: "las estructuras y prácticas, las reglas y normas que las guian, y el lenguaje y símbolos que median las interacciones sociales dentro de dichas estructuras y prácticas, en instituciones tales como el Estado, la familia y la sociedad civil, así como en el trabajo". Ibidem, p. 42 . 
y valores a los cuales quiere proyectar su vida y que cuente con los medios necesarios para llevar sus fines a cabo.

Para poder considerar, sin ningún tipo de eufemismos, a una persona como inalienable, se requiere que ésta goce de un minimo margen de autonomía e independencia que le permita sustraerse de la relación de dependencia de los intereses y fines de otras personas. Por el contrario, cuando el hombre se ve constreñido de una manera radical y total a sus necesidades más básicas de subsistencia se torna en un blanco fácil para que otros, reduciéndolo a una mercancía más, exploten sus cualidades y esfuerzo para un beneficio personal. En este sentido Marion Young afirma que en nuestras sociedades contemporáneas la explotación y la marginación de ciertos grupos de personas son dos caras de la opresión. La primera, en tanto que ciertos grupos de personas, como mujeres, minorias raciales, migrantes o indigenas, se ven obligados a realizar trabajos poco significativos en beneficio de otros y, la segunda, en tanto que la estructura económica, educativa y social excluye a una cierta categoría de personas de la participación útil de la sociedad, quedando así potencialmente sujetas a graves privaciones materiales e incluso al exterminio. El fenómeno de la opresión rompe por definición el principio de igualdad en derechos en tanto que su caldo de cultivo es la existencia de posiciones asimétricas entre la personas en relación con las oportunidades con las que cada uno cuenta para desarrollarse a sí mismo.

Por otro lado, la exigencia de la ininstrumentabilidad de la persona supone no sólo no sea tratada como un medio o instrumento al servicio de los fines de otros, sino además, que como fin en sí misma, la persona pueda elegir los fines hacia los cuales desea conducir sus actos y con base en los cuales construye su concepto de vida buena. El fenómeno de la dominación, tal y como es comprendido por Young, implica, por el contrario, la imposición que una persona hace de sus propios fines a otro y el respectivo sometimiento de esa persona a los fines de otros. Ya sea a través del imperialismo 
cultural, de la constante burocratización de los espacios vitales o de la imposición de un conjunto de patrones de conducta encaminados a hacer de las personas meros consumidores, las formas de dominación contemporánea tienen a reducir la autonomía de las personas y a aniquilar la pluralidad y diversidad que existe entre ellas.

De esta manera, una distinción establecida en la ley que tenga como objeto, o bien, que tenga por efecto, limitar o restringir sustancialmente las oportunidades de auto desarrollo y autodeterminación de las personas debe ser considerada como discriminatoria, aun cuando el fin que persigue sea aparentemente legítimo. 